\title{
Introducing Peer Review
}

\section{Goals}

For both instructors and students, peer review (PR) can be unpredictable, by turns successful and confounding, useful and useless. Despite the inconsistency and frustration that often comes with it, students still see the potential for PR to facilitate their development as writers. As one student put it, "for me, [peer review] was a frustrating process because I feel like it didn't have to be a frustrating process."

The goal of this lesson plan is to lay the foundation for a PR process that supports key threshold concepts in the writing classroom: that writing is social and collaborative; that writers must consider audience, and that academic discourse is a conversation to which they may add their own voices.

In this lesson plan, students first talk through their previous experience, positive and negative, with peer review. This allows students to air common challenges. It also signals that the PR they will do in your class will attempt to account for these challenges, and so will not be just another "hit or miss" PR session. Second, students gain a baseline understanding that PR is not about correction and it is not only about the feedback they receive, but the transferrable practice of giving persuasive and useful feedback.

By the end of the session, students will be able to or will begin to:

- Reflect critically on their own experience as peer reviewers and writers

- Understand that their peers have valid feedback to offer them

- See PR as a collaborative act focused on ideas and author goals rather than locating (what they believe are) sentence-level errors

- Model their own comments and feedback on specific examples

\section{Lesson Plan (for a 50-minute section of first-year writing or any writing/English class)}

Before this class session, have students read Richard Straub's "Responding — Really Responding - to Other Students' Writing." You may choose to assign some form of response to the reading, but you do not need to.

Part I: Previous Experience 
1. Briefly introduce peer review (PR), also known as peer response, peer editing, workshop. Make a quick argument about why you think PR is a useful activity. ${ }^{1}$

2. Now ask students to take three to five minutes to jot down notes on the following question: What is your specific experience with PR? List a few pros and cons.

a. Depending on time and context, you may either ask students to speak to their neighbors about what they jotted down regarding PR or you may jump to step three.

3. Ask a student to volunteer to record the discussion on a white/chalk board. On the left, make a column for "Pros," in the middle make one for "Experience," and on the right, make one for "Cons."

4. Now invite students to share their experiences and thoughts.

5. After students share, help them condense their comments to make them "pithy." Making the comments pithy is a fun side challenge. If the conversation lags or students are not responding to one another, ask students to raise their hands if they have similar experience and then invite them to share a specific story about that experience.

6. Once you have filled up the board, spend a couple minutes noting common experiences.

\section{Part II: Responding to Straub}

7. Explain that now you'll be turning to the Straub text and that you will be attempting to connect what the students put on the board with what Straub suggests.

8. Have students take out their Straub text and spend three to five minutes responding to the following points. (Again, depending on context, you may put students into groups or skip to step nine.)

a. What do you think are Straub's main points? Which points do you think are most important and why?

b. Mark two or three quotations that you found interesting or funny.

c. Imagine Straub is in the room. What further questions do you have for him? What doubts do you still hold about PR?

9. Invite students to share their responses with the class to facilitate a discussion. Connect Straub's key points to their experience. For example, they might have written

\footnotetext{
${ }^{1}$ This quick argument is important because students often do not understand why instructors assign peer review. If students don't understand the purpose and goals, they may dismiss PR based on their previous experiences with it or based on the notion that their peers will have nothing of value to offer them in terms of feedback.
} 
down that Straub suggests that reviewers should be aware of the context and goals of the review. Turn here to Straub's humorous assertions about how students should not "seek out and destroy all errors," since (a) that is not the point of PR and (b) it may not be what the readers want.

\section{Part III: To Conclude}

10. Wrap up the conversation by highlighting key themes or points (e.g., that a peer reviewer is "there to play back to the writer how [they] read the paper" (137, my bolding)) and by talking about how you have attempted to account for challenges and facilitate useful PR.

a. You may also now outline the PR process the students will carry out, referencing student's previous experience and Straub's suggestions.

b. You may also have students take five minutes to write down what they have learned from this class about PR and how they plan to carry out PR.

c. For next time, you may have the students create guidelines for PR to be used in the class.

\section{Key Quotations from Straub that you may refer to during the discussion}

1. "A friendly reader," "a test pilot" (137)

2. Don't "seek out and destroy all errors and problems" (137)

3. "You're not an editor" or a teacher.

4. "Be reluctant at first even to say how to revise if the paper were yours" (137)

5. "You're there to play back to the writer how you read the paper: what you got from it; what you found interesting, where you were confused; where you wanted more" (137 and 141)

6. "Don't try to cover everything” (139)

7. "Address issues that are most important to address in this paper, at this time" (139)

8. "Sound like you normally sound when you're speaking to a friend or an acquaintance" (139)

9. "Be always of two (or three) minds about your response to the paper" (140) 